Supporting Information

for

\title{
Biphenolate Phosphine Complexes of Group 4 Metals
}

by

Lan-Chang Liang, ${ }^{*}, \dagger$ Yu-Ning Chang, ${ }^{\dagger}$ and Hon Man Lee ${ }^{\ddagger}$

${ }^{\dagger}$ Department of Chemistry and Center for Nanoscience \& Nanotechnology, National Sun Yat-sen University, Kaohsiung 80424, Taiwan

${ }^{\ddagger}$ Department of Chemistry, National Changhua University of Education, Changhua 50058, Taiwan

\section{Content}

Figure S1. Variable-temperature ${ }^{1} \mathrm{H}$ NMR spectra of $[\mathrm{OPO}]_{2} \mathrm{Zr}\left(\mathrm{OH}_{2}\right)$ in toluene- $d_{8}$. * denotes residual pentane signals. 

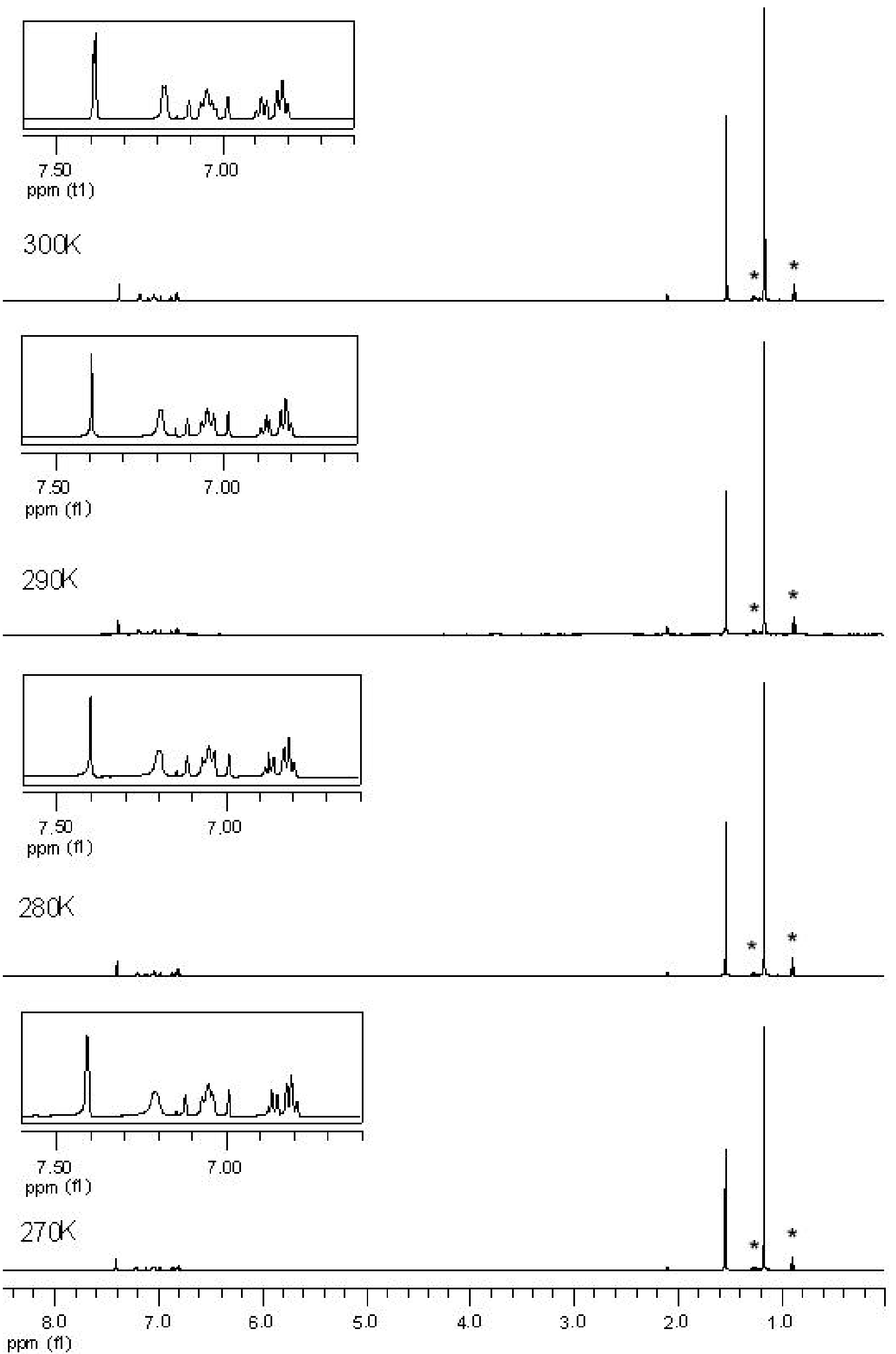


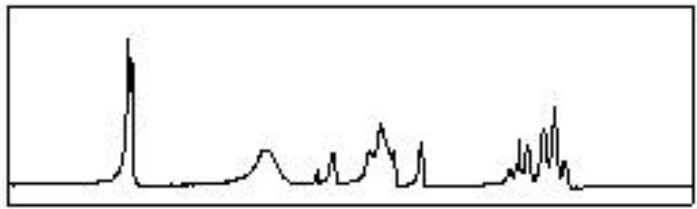

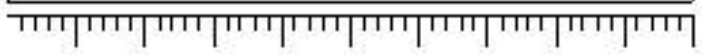

7.507 .407 .307 .207 .107 .006 .906 .806 .70 spm (t1)

$260 \mathrm{~K}$
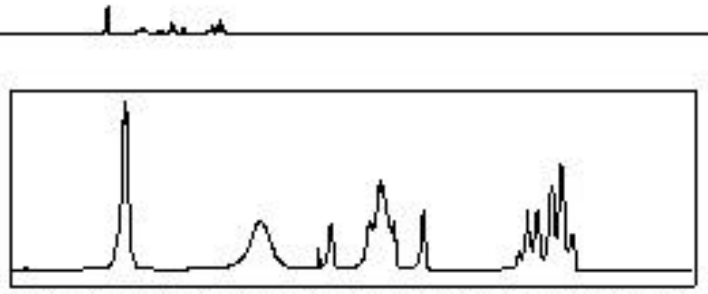

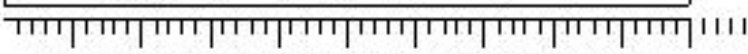

7.507 .407 .307 .207 .107 .006 .906 .806 .70 opm (t 1)

$250 \mathrm{~K}$

Lurectar

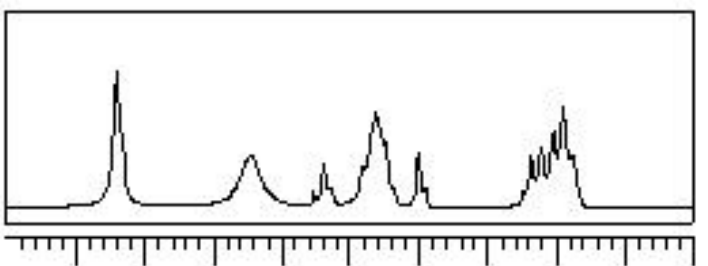

7.507 .407 .307 .207 .107006 .906 .806 .70 opm (t1)

$240 \mathrm{~K}$

Lrukn

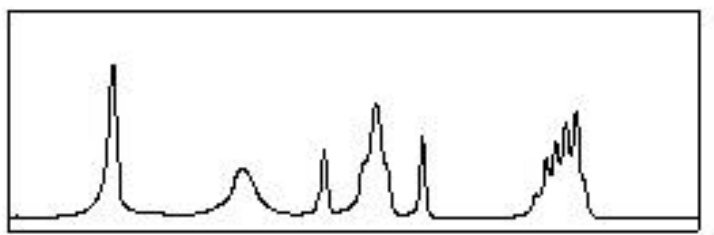

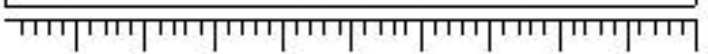

7.507 .407 .307 .207 .107 .006 .906 .806 .70 opm (t1)

$230 \mathrm{~K}$

Luthes

80

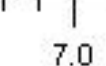

7.0

6.0

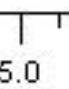

$\left.\right|_{4.0} ^{1}$
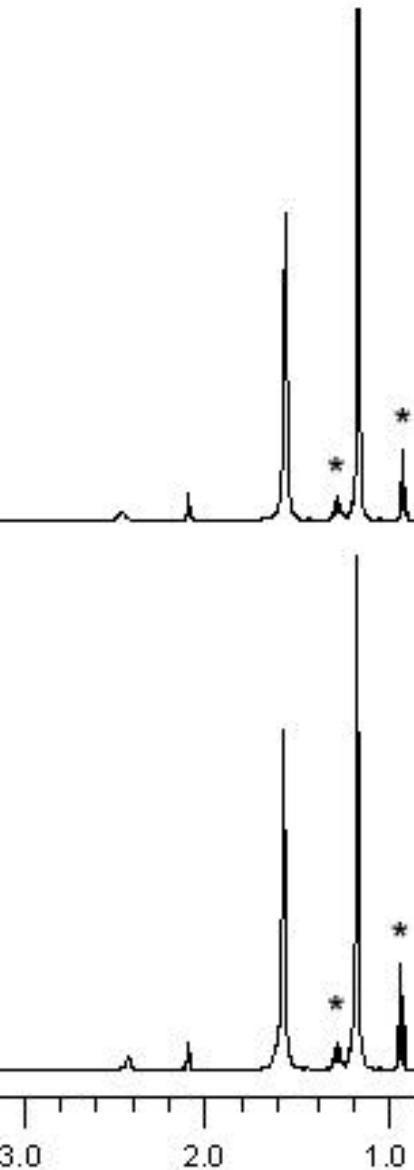

ppm (f1) 


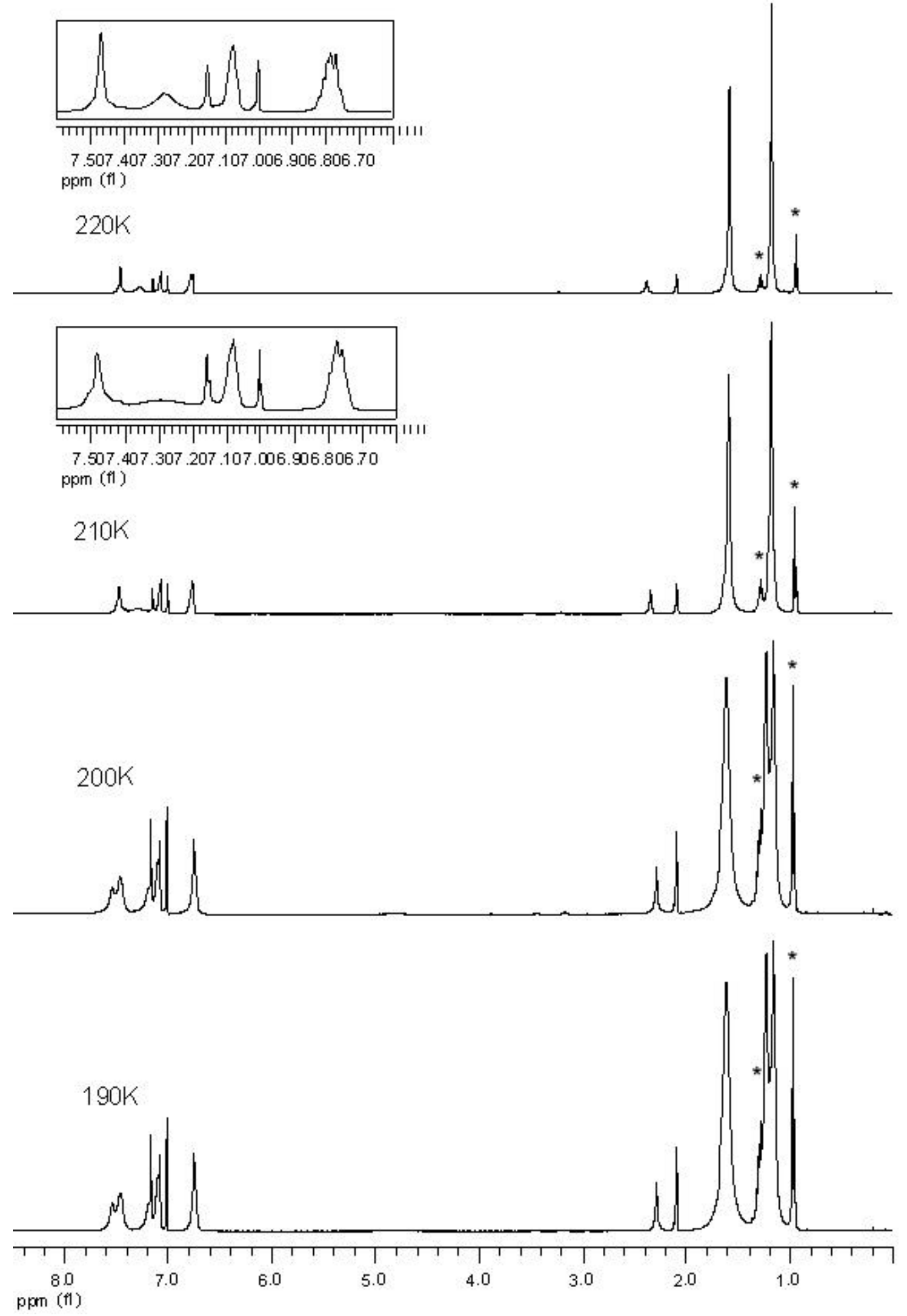

